\title{
ПОТЕНЦИАЛ РАЗВИТИЯ КОМПЕТЕНЦИЙ МЕНЕДЖЕРОВ В БЕЛОРУССКОЙ ЭКОНОМИКЕ
}

\section{Н.В. Маковская*}

Представлены результаты научного исследования компетенций менеджеров в национальной экономике Беларуси. Определены критерии и шкала оценки развитости и наличия набора их профессиональных навыков и компетенций. Выявлены тенденции и пороги критичности в развитии профессиональных компетенций в условиях инновационности и цифровизации экономики Беларуси.

Ключевые слова: менеджер, профессиональные компетенции, производительность труда, виды экономической деятельности, рабочее время, рынок труда.

JEL-классификация: J24, J31, J44.

DOI: $10.46782 / 1818-4510-2021-4-41-54$

Материал поступил 25.08.2021 2.

\section{Актуальность и методология исследования}

Актуальность исследований менеджериального труда, его содержания и компетенций связана с тем, что организации тратят значительные ресурсы на оплату труда работников, занимающих руководящие позиции. Это делает значимой оценку производительности их труда. Выполнение менеджерами трудовых функций приводит к разным результатам. Так, результат труда менеджеров в производственном цеху может быть выражен в виде определенного количества изготовленных деталей подчиненными ему рабочими, а труда менеджера по персоналу в виде количества сотрудников, прошедших повышение квалификации, или низкого уровня текучести кадров и др. Все это говорит о наличии принципиальных отличительных признаков менеджериального труда (в сравнении с другими категориями работников). Такого рода отличия связаны с особенностями формирования и развития компетенций менеджеров.

Набор и развитость компетенций определяют качество продукта труда менеджера - управленческое решение, правиль- ное принятие которого в современных условиях в большей степени зависит от таких компетенций, как soft skills («мягкие» навыки). Они характерны только для конкретной профессии, работы в особых профессиональных условиях и позволяют реализовывать управленческие функции эффективно и полностью. Такого рода компетенции актуальны в работе с коллективом и командой (каждый менеджер общается с коллегами, а иногда еще и с клиентами, партнерами). Менеджер должен уметь договариваться с ними, аргументировать свою позицию. Кроме того, «мягкие» навыки это современная форма работы с информацией, которая генерируется не только при визуальном общении, но и в онлайн-пространстве.

Именно soft skills участвуют в процессе принятия управленческого решения, формируют тип предпринимательского поведения менеджера, которое заключается в инициировании перемен в целях развития организации, адаптации к изменяющимся условиям внешней среды, в поиске новых идей для реализации этих перемен. Результат правильно принятого управленческого

* Маковская Наталья Владимировна (maknata@mail.ru), доктор экономических наук, профессор, Могилевский государственный университет им. А.А. Кулешова (г. Могилев, Беларусь). https://orcid.org/0000-0003-2909-2925 
решения - рациональное использование ресурсов (распределение рабочего времени, разделение труда, координация деятельности сотрудников и т. п.). Новизна принятого управленческого решения зависит от качества и набора soft skills, которыми владеет менеджер. Именно soft skills классифицируют менеджериальный труд как инновационный.

Современные исследования компетенций и труда менеджеров в целом сводятся к оценкам набора функций менеджеров ${ }^{1}$ (Друкер, 2004): сбор, систематизация и организация информации, необходимой для принятия управленческих решений; планирование собственной работы и работы подразделения, что включает постановку целей и задач, анализ информации (документации, литературы), проведение расчетов при необходимости, подготовку плановых документов (решений); согласование и утверждение решений; организация работ по реализации принятых решений (выполнению планов); подготовка отчетной документации, сформированной в рамках принятых решений.

Существуют направления исследований, которые систематизируют и оценивают только наборы управленческих компетенций (Ноакк, Костина, Ларин, Знаменская, 2020; Laguna, Wiechetek, Talik, 2012; Уиддет, Холлифорд, 2008 и др.). В структуре управленческих компетенций выделяют три составляющих: видение развития предприятия, организация работы, кадровое управление. Так, на этой основе авторы M. Robinson, P. Sparrow, C. Clegg, K. Birdi (2005) выделяют шесть кластеров управленческих компетенций. К их числу они относят личные качества, управление проектами, когнитивные стратегии, познавательные способности, технические способности и коммуникацию. В настоящее время появился подход, позволяющий оценить соотношение компетенции менеджеров с успешностью бизнеса и персональной эффективностью. Так, в работе M. Laguna, M. Wiechetek, W. Talik (2012) анализируется, как управленческие компетенции

${ }^{1}$ Нестерова О.В. 2016. Handbook по дисциплине «Модели профессиональных компетенций в управлении персоналом». Москва: Московский финансово-промышленный университет «Синергия». 35 с. руководителя (в том числе лидерство и организаторские способности) соотносятся с успешностью бизнеса малых и средних предприятий.

Обобщая содержание научных исследований, следует определять характеристики труда менеджеров, предполагающие наличие у них компетенций: а) характеристики работников, позволяющие им демонстрировать лояльное корпоративное поведение и высокую производительность труда; б) способности работников действовать в соответствии со стандартами, принятыми в организации.

Наиболее тиражируемым и часто используемым в исследовательской практике является подход Л.М. Спенсера-мл., C.M. Спенсера (2010), выделяющий 5 типов базовых качеств (компетенций): а) мотивы то, о чем работник думает или чего хочет постоянно, что вызывает действия; б) психофизиологические особенности (свойства) - физические характеристики и соответствующие реакции на ситуации или информацию; в) Я-концепция - установки, ценности, образ Я-работника (представление о себе); г) знание - информация, которой человек обладает в специальных областях; д) навык способность выполнять определенную физическую или умственную задачу.

Профессиональные характеристики компетенций менеджеров целесообразно классифицировать в рамках двух групп в зависимости от критерия исполнения работы. Группа 1 - пороговые компетенции. Являются неотъемлемой характеристикой. Каждый выполняющий работу должен быть хотя бы минимально эффективен, при этом нет разграничений средних исполнителей и наилучших. Группа 2 - дифференцирующие компетенции. Эти факторы отличают наилучших исполнителей от средних. Например, ориентация на достижение, выраженная в том, что человек ставит перед собой цели выше, чем требует компания, является компетенцией, которая отличает лучших сотрудников от средних (Там же).

Данные теоретические подходы лежат в основе современных концепций исследования компетенций (навыков) менеджеров. Самой популярной является концепция мониторинга и использования soft skills - это унифицированные навыки и личностные ка- 
чества, которые повышают эффективность работы и взаимодействия с другими людьми. К ним можно отнести управление личным развитием, умения оказать первую помощь, грамотно управлять своим временем, убеждать, вести переговоры, лидерство и др. Современные методики исследования таких навыков представлены через множество корпоративных анкет (например, версии анкет института Макса Планка в Мюнхене, Boston Consulting Group, американский ресурс CareerBuilder и др.). Объединяет их все одинаковое использование критериев и признаков (как правило, 50-60 наименований), которые объединены в блоки (группы) компетенций. «Мягкие» навыки менеджеры оценивают самостоятельно по причине того, что формируются эти компетенции под воздействием личного опыта, психофизиологических характеристик самих менеджеров. Пример таких объединенных групп компетенций: «личная динамика» (чувство ответственности, стремление к достижениям, высокая мотивация и др.); «межличностные отношения» (контактность, сопереживание и др.); «удовлетворенность работой» (достижение показателей, объективность и др. $)^{2}$.

Особенностью данного подхода является то, что в отличие от hard skills (технических навыков) уровень владения soft skills сложно измерить, а потому их трудно обнаружить в процессе отбора кандидатов. Наличие таких навыков у менеджеров обычно выявляется в процессе их опроса, который, в свою очередь, позволяет получить более полное представление о способе их мышления, мотивации, отношении к команде и побудительных мотивах для поступков.

В белорусской исследовательской практике впервые предпринята попытка оценить уровень развитости и состоятельности навыков менеджеров в условиях национальной экономики в рамках отдельных организаций. В качестве основного инструмента выступил опросник, разработанный Лабораторией компетенций SOFT SKILLS (совместный проект Южного Федерального Университета (ЮФУ) и Центра карье-

${ }^{2}$ Soft skills: ключ к карьере. URL: http://www.propersonal.ru/jour-nal/303/7811/; Soft skills: самое важное о гибких навыках. URL: http://4brain.ru/blog/soft-skills ры ЮФУ). Его методическая основа полностью соответствует концепции мониторинга и использования soft skills.

Отбор белорусских менеджеров проводился с учетом их менеджериального опыта и профессиональных характеристик. Управленческий потенциал оценивался уровнем менеджеров среднего звена, так как численная и профессиональная представительность этой категории является наиболее адекватной для экономической оценки. Учет таких особенностей позволил сделать выборку респондентов более репрезентативной для белорусских социально-экономических и институциональных условий.

\section{Оченка компетенций белорусских менеджеров. Общая характеристика респондентов, инструменты и описание данньх}

Общая информационная характеристика анкетного опроса представляет собой определение компетенций менеджера в параметрах «полностью (не полностью) соответствует», что позволило собрать информацию по направлениям:

- степень развитости компетенций, которые оценивались в баллах по шкале Лайкерта, после чего подсчитывалось количество баллов по каждой из компетенций (на основании 55 утверждений менеджерам среднего звена предлагалось оценить степень развитости своих управленческих компетенций). Всего оценивались 11 управленческих компетенций (многоуровневое решение проблем, критическое мышление, креативность, управление людьми, эмоциональный интеллект и др.). Далее на основе полученной суммы баллов определялся один из трех уровней развития компетенций менеджеров среднего звена - начальный уровень, уровень развития или уровень опыта;

- умение планировать работу менеджера с распределением менеджериальных функций;

- уровень приоритетности постановки задач подчиненным исполнителям и подчиненным структурным подразделениям;

- степень выполнения дополнительных функций и функций контроля и мотивации подчиненными сотрудниками; 
- оценка выполнения функциональных действий менеджера (распределение работ между исполнителями, обеспечение ресурсами, разработка документации и предложений, анализ показателей и т. п.);

- наличие возможности саморазвития (самообразования);

- дополнительная информация о респонденте (пол, возраст, отраслевая принадлежность организации, управленческий стаж, количество подчиненных и т. п.).

Была проведена оценка рабочего времени менеджера с целью выявления рациональности его использования, видимых затрат и административных барьеров, что позволило получить фотографию дня менеджера (с анализом личного и рабочего времени) и сделать оценку характера работы с определением ее важности и степени контролируемости.

Дополнительным инструментом для оценки тайм-менеджмента руководителей стала специальная программа «Бизнес-время», доступная и в мобильных устройствах. С периодичностью в 15 мин. анкетируемому предлагаются закрытые вопросы об использовании рабочего времени. Учитывая форму сбора данных, они были обработаны достаточно быстро. Методика получила апробацию на ряде российских и белорусских предприятий.

В исследовании приняли участие менеджеры организаций разной отраслевой принадлежности: 113 чел. (из них 42,7\% - мужчины и 57,3\% - женщины) от Республики Беларусь, представляющих предприятия 13 видов экономической деятельности (ВЭД) национальной экономики. Наибольшее количество менеджеров-респондентов - из обрабатывающей отрасли промышленности, торговли и сферы образования. В разрезе данных отраслей представлены как самостоятельные организации $(81,4 \%)$, так и их филиалы (подразделения) (18,6\%). Численность персонала, где работают менеджеры, варьируется: более 1000 чел. (59,8\% менеджеров), 100-500 чел. (24,8\%), менее 100 чел. (15,4\%). По возрастному критерию респонденты распределились следующим образом (табл. 1).

Как видим, выборка абсолютно неоднородна и охватывает все возрастные категории менеджеров. В полном объеме присут- ствует самый активный трудоспособный возраст в категории 31-45 лет и 46-60 лет. В выборке представлены и менеджеры старше трудоспособного возраста, что подтверждает ее репрезентативность.

Возрастной критерий выборки дополнен управленческим стажем менеджеров, который коррелирует с их возрастом (табл. 2). Большая часть респондентов - со стажем работы более 10 лет. Это позволило исследовать проявление компетенций менеджеров, реализацию их управленческого потенциала более объективно и полно. Значимым является и то, что в выборке представлены и «молодые» по стажу работники. В результате были определены сравнительные преимущества в использовании управленческого потенциала менеджеров с разным профессиональным стажем, которые распределены по функциональным профилям следующим образом (табл. 3 ).

В выборке представлены менеджеры основного административно-экономического функционала, реализующие все виды компетенций, имеющих место в белорусских организациях, главным образом - с профессиональными компетенциями в сфере кадровой работы и финансово-экономического управления. Уровень кадровой подчиненности представлен многопланово (от 5 до 20 чел.).

Более $87 \%$ менеджеров отметили, что их уровень управленческого образования под-

Таблица 1

Возраст менеджеров-респондентов

\begin{tabular}{|l|c|}
\hline \multicolumn{1}{|c|}{ Возраст, лет } & Количество, чел. \\
\hline До 30 & 4 \\
\hline $31-45$ & 40 \\
\hline $46-60$ & 58 \\
\hline Старше 60 & 11 \\
\hline
\end{tabular}

Источник. Авторская разработка по результатам мониторинга белорусских менеджеров.

Таблица 2

Управленческий стаж менеджеров-респондентов

\begin{tabular}{|l|c|}
\hline \multicolumn{1}{|c|}{ Стаж } & Количество, чел. \\
\hline До 1 года & 5 \\
\hline 1-2 года & 11 \\
\hline 3-5 лет & 15 \\
\hline 6-10 лет & 17 \\
\hline Более 10 лет & 65 \\
\hline
\end{tabular}

Источник. Авторская разработка по результатам мониторинга белорусских менеджеров. 


\begin{tabular}{|c|c|}
\hline \multicolumn{2}{|c|}{$\begin{array}{c}\text { Таблица } 3 \\
\text { Распределение менеджеров } \\
\text { по функциональным профилям и количеству } \\
\text { подчиненных сотрудников }\end{array}$} \\
\hline $\begin{array}{c}\text { Функциональный профиль } \\
\text { менеджера }\end{array}$ & Количество, чел. \\
\hline Маркетинг и продажи & 18 \\
\hline Техника и технология & 12 \\
\hline Качество & 6 \\
\hline Логистика & 3 \\
\hline Персонал & 25 \\
\hline Учет, экономика, финансы & 26 \\
\hline Право & 1 \\
\hline Безопасность & 4 \\
\hline IT & 5 \\
\hline Другое & 13 \\
\hline \multicolumn{2}{|l|}{$\begin{array}{c}\text { Количество подчиненных } \\
\text { сотрудников, чел. }\end{array}$} \\
\hline До 5 & 32 \\
\hline $6-10$ & 24 \\
\hline $11-20$ & 21 \\
\hline Более 20 & 36 \\
\hline
\end{tabular}

Источник. Авторская разработка по результатам мониторинга белорусских менеджеров.

твержден дипломами о профессиональной переподготовке, и только 3,3\% имеют базовое (бакалавриат) управленческое образование. Респонденты указывали и на то, что их образование в сфере управления сформировано в рамках курсов повышения квалификации, семинаров, тренингов. У некоторых вообще нет специального образования.

Следует констатировать, что у белорусских менеджеров наблюдается тенденция отсутствия базового управленческого образования. Данная компетенция для этой категории работников является сопутствующей их основному (базовому) диплому, что подтверждается и распределением респондентов по их потребности в саморазвитии. Так, 41,5\% менеджеров указали на то, что они регулярно просматривают литературу по вопросам управления, и $40,7 \%$ читают хотя бы несколько публикаций в год. Такая статистика констатирует: у белорусских менеджеров все еще недостаточный образовательный уровень для современной системы управления.

Анализ описательной статистики указывает в целом на хороший уровень репрезентативности результатов, полученных с помощью данной выборки респондентов. Сложилось представление о профессиональном функционировании менеджеров среднего звена на разномасштабных предприятиях, об их возрасте, профессиональной подготовке, количестве подчиненных сотрудников и сферах, в которых они работают, и т. п.

Анкетирование менеджеров проводилось с использованием 55 вопросов-критериев для определения степени развитости их управленческих компетенций по 11 блокам (табл. 4). Ответы оценивались в баллах по шкале Лайкерта, после чего подсчитывалось количество баллов по каждой из компетенций. На основе полученной суммы баллов определялся один из трех уровней развития компетенций менеджеров среднего звена:

a) начальный уровень - менее 15 баллов: менеджер не владеет компетенцией. Характерные для компетенции поведенческие проявления и модели он демонстрирует редко или не демонстрирует совсем. Кроме того, менеджер придерживается негативных поведенческих моделей, не понимает важности компетенции, не пытается ее применять и развивать;

б) уровень развития - 16-21 балл: менеджер владеет компетенцией ограниченно, в виде отдельных элементов. Компетенция проявляется не в нестандартных, сложных ситуациях, а только в простых или знакомых;

Таблица 4

Блоки компетенций менеджеров

\begin{tabular}{|c|l|}
\hline $\begin{array}{c}\text { Номер } \\
\text { блока }\end{array}$ & \multicolumn{1}{|c|}{ Компетенция (k) } \\
\hline 1 & $\begin{array}{l}\text { Комплексное многоуровневое решение } \\
\text { проблем }\end{array}$ \\
\hline 2 & Критическое мышление \\
\hline 3 & Креативность \\
\hline 4 & Управление людьми \\
\hline 5 & Сотрудничество с другими \\
\hline 6 & Эмоциональный интеллект \\
\hline 7 & Суждение и принятие решений \\
\hline 8 & Клиентоориентированность \\
\hline 9 & Умение вести переговоры \\
\hline 10 & Когнитивная гибкость \\
\hline 11 & Эффективный поиск работы \\
\hline
\end{tabular}

Источник. Авторская разработка по результатам мониторинга белорусских менеджеров. 
в) уровень опыта - 22 и более баллов: менеджер успешно использует компетенцию для решения стандартных рабочих задач. В новых, нестандартных ситуациях компетенция носит фрагментарный характер. Отсутствуют проявления начального уровня развития компетенций, негативные поведенческие модели. Менеджер четко осознает суть компетенции, демонстрирует модели поведения, подтверждающие ее. Сознательно отслеживает собственные поведенческие проявления компетенции и окружающих.

\section{Оценка компетенций менеджера в рамках видов экономической деятельности и функционального профиля}

В выборке больший состав исследуемых менеджеров представлен обрабатывающими производствами (53 чел.), социальной сферой (образование - 23 чел.) и сферой услуг (торговля - 13 чел.). Однако самый высокий уровень компетенций соответствует менеджерам, представляющим профессиональную деятельность в научно-технической сфере. Диаграмма (рис. 1), построенная по убывающему принципу, четко указывает на распределение компетенций менеджеров по видам экономической деятельности в белорусской экономике. Так, уровень компетенций, характеризующий накопленный опыт и в нашем исследовании классифицируемый как са-

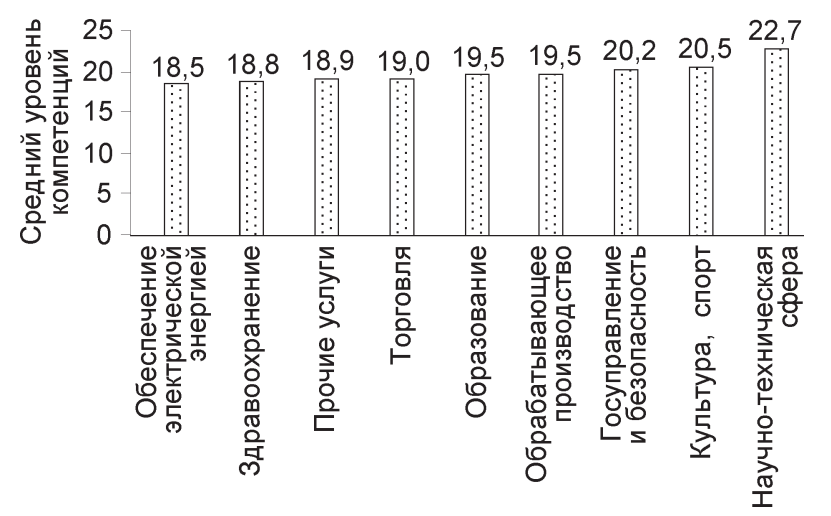

Рис. 1. Распределение компетенций менеджеров по видам экономической деятельности в экономике Беларуси

Источник. Авторская разработка по результатам мониторинга белорусских менеджеров. мый высокий (более 22 баллов), представлен в научно-технической сфере Беларуси (средний балл оценки - 22,7).

Следует отметить, что в таких высококвалифицированных ВЭД, как здравоохранение и образование, менеджеры проявляют средний уровень своих компетенций (здравоохранение - 18,8, образование - 19,5 балла). Причинами такого уровня компетенций выступает множество факторов, которые должны быть объектом дальнейших научных исследований. Однако следует предположить, что одна из основных причин - высокая степень прогрессивности и инновационности в развитии этих сфер, которая влечет моральное устаревание профессиональных знаний и компетенций.

Исследование компетенций у менеджеров по разным профессиональным профилям (маркетинг и продажи; техника и технологии; качество; логистика; персонал; учет, экономика, финансы; право; безопасность; IT и др.) позволило заключить следующее (рис. 2):

- менеджеры в рамках разных профессиональных профилей не имеют статистически значимых различий между собой по общему уровню компетенций. Несколько выделяются менеджеры по профилю «качество», у которых в выборке максимальный балл (средний балл - 20,9), и менеджеры с наименьшим баллом $(18,8)$ по профилю «безопасность»;

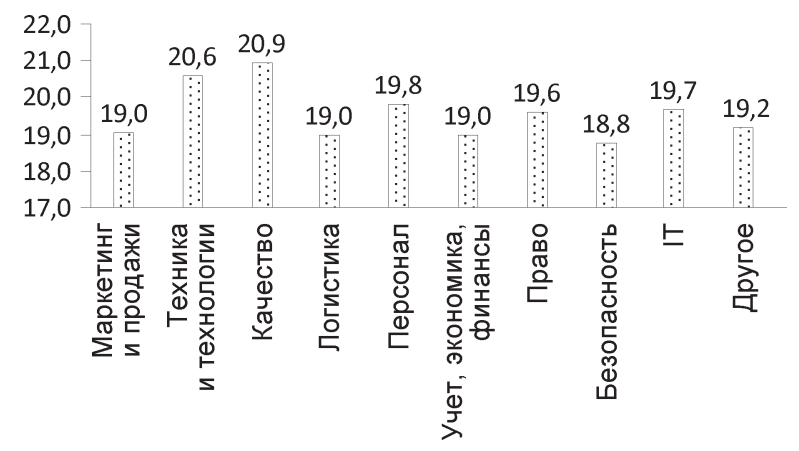

Рис. 2. Распределение средних баллов компетенций менеджеров в рамках профессиональных профилей

Источник. Авторская разработка по результатам мониторинга белорусских менеджеров. 
- оценка всех блоков компетенций $(\mathrm{k})$ у менеджеров по разным профилям показывает, что у них максимально представлены компетенции k11 (эффективный поиск работы) и $\mathrm{k} 8$ (клиентоориентированность) (рис. 3).

Минимальный уровень развитости у исследуемых менеджеров - компетенций k3 (креативность) и k9 (умение вести переговоры). Следует отметить, что набор этих компетенций является обязательным для условий инновационного развития национальных экономик.

У белорусских менеджеров среднего звена самый высокий уровень накопленных через опыт компетенций (в оценке выше 22 баллов) наблюдается в таких позициях, как: сотрудничество с другими людьми (k5), эмоциональный интеллект (k6), клиентоориентированность (k8), эффективный поиск работы (k11). Это скорее можно интерпретировать как «анахронизм» постсоветской экономики (конец 90-х - начало 2000-х), когда развитие белорусского общества было нацелено на формирование рыночной экономики, выход на новые рынки, создание новых рабочих мест и стабильность национального рынка труда. В современных условиях цифровой экономики и экономики знаний такие компетенции практически не востребованы.

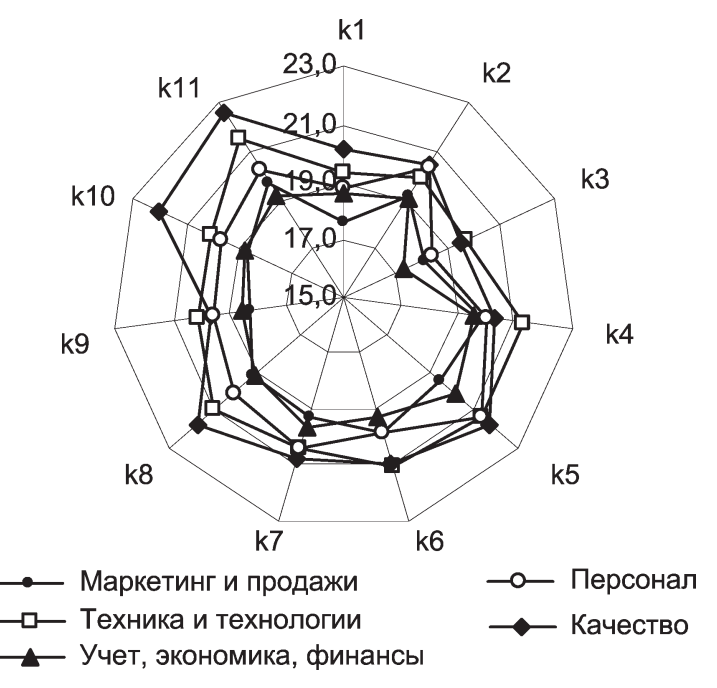

Рис. 3. Представленность компетенций (k) у менеджеров разных профилей

Источник. Авторская разработка по результатам мониторинга белорусских менеджеров.
Наши исследования менеджеров среднего звена свидетельствуют о том, что:

такие компетенции, как комплексное многоуровневое решение проблем $(\mathrm{k} 1)$, управление людьми (k4), суждение и принятие решений $(k 7)$, умение вести переговоры (k9), проходят этап развития, в рамках которого менеджер очень ограниченно владеет этой компетенцией, не имеет опыта ее использования в нестандартных ситуациях и форс-мажора;

компетенции, сопровождающие создание и обслуживание инноваций (креативность (k3) и когнитивная гибкость (k10)), находятся в стадии зарождения или начального уровня, в рамках которого менеджер ими не владеет и поэтому не формирует модели их использования. Кроме этого, менеджер к такого рода компетенциям может быть антогоничен, демонстрировать их непринятие и нежелание формировать.

Уровень профессионального образования менеджеров характеризуется следующими данными, полученными в рамках мониторинга респондента (табл. 5).

В компетенциях менеджеров по направлениям профессионального образования нет статистически значимых различий, так как практически все (99 чел.) прошли профессиональную переподготовку и имеют сертификаты менеджеров в качестве дополнительных к базовому образованию. Только 3 чел. в выборке менеджеров получили высшее базовое образование в сфере управления.

Таблица 5

Профессиональное образование менеджеров в сфере управления и уровень их компетенций

\begin{tabular}{|l|c|c|}
\hline \multicolumn{1}{|c|}{ Образование } & $\begin{array}{c}\text { Количество, } \\
\text { чел. }\end{array}$ & $\begin{array}{c}\text { Уровень } \\
\text { компетенций }\end{array}$ \\
\hline $\begin{array}{l}\text { Высшее образование } \\
\text { в сфере управления }\end{array}$ & 3 & 19,74 \\
\hline $\begin{array}{l}\text { Профессиональная } \\
\text { переподготовка }\end{array}$ & 99 & 19,06 \\
\hline $\begin{array}{l}\text { Курсы повышения } \\
\text { квалификации }\end{array}$ & 8 & 19,38 \\
\hline $\begin{array}{l}\text { Участие } \\
\text { в семинарах, } \\
\text { тренингах }\end{array}$ & 3 & 20,1 \\
\hline
\end{tabular}

Источник. Авторская разработка по результатам мониторинга белорусских менеджеров. 
Таким образом, информативным является следующее: а) для условий национальной экономики Беларуси высшее образование в сфере управления не является приоритетным, оно скорее имеет дополнительный характер к базовому образованию; б) все виды профессионального образования в сфере менеджмента формируют одинаковый уровень компетенций менеджеров. Однако высшее образование дает несколько больший уровень по причине его системности и фундаментальности.

\section{Уровень развития компетенций и результативность работь белорусских менеджеров}

Оценка стиля работы менеджеров проводилась с использованием опроса, позволяющего собрать информацию по направлениям: количество и принципы выполнения задач, время выполнения задач, период и организация планирования управленческой деятельности, форма постановки задач и их приоритетность для подчиненных, количество невыполненных задач, контроль подчиненных и т. п.

Соотношение уровней развития компетенций менеджеров и выполнения ими запланированных задач с учетом соответствующей градации (выполнение на 90\% и более, 70-80\%, 50-60\%, менее 50\%) показало (рис. 4), что наиболее компетентные менеджеры решают больше запланированных задач. Взаимосвязь первых трех имеет статистическую значимость $(p<0,05)$.

При этом остается вопрос относительно невыполнения задач (менее 50\%) менед-

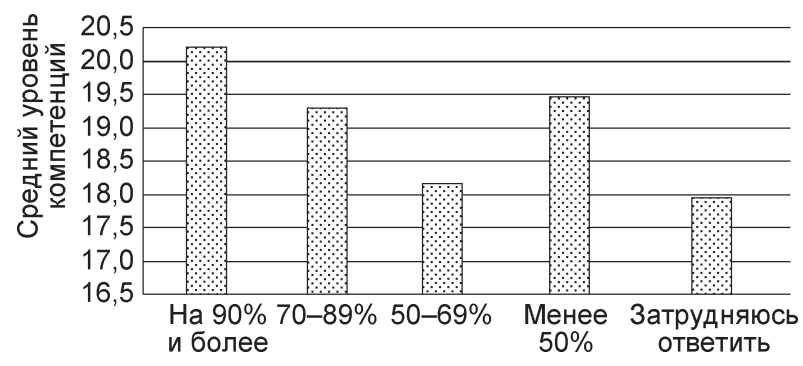

Рис. 4. Соотношение уровней развития компетенций менеджеров и выполнения ими запланированных задач

Источник. Авторская разработка по результатам мониторинга белорусских менеджеров. жерами, у которых средний уровень компетенций составляет 19,5 балла (по выборке это второй по значимости результат развития). Данный факт требует дальнейшего исследования.

В целях определения четкой взаимосвязи долей (в \%) выполнения поставленных задач в общем объеме планируемой работы и уровня развития компетенций у менеджеров была проведена оценка корреляционных связей, которая позволила констатировать, что взаимосвязи повторяются для каждой компетенции и являются статистически значимыми для $\mathrm{k} 3, \mathrm{k} 4, \mathrm{k} 6, \mathrm{k} 9$, k11 (табл. 6).

Результаты оценки указывают на то, что:

- существует объективная положительная зависимость между полнотой выполнения (в \%) запланированных задач и наличием развитых компетенций у белорусских менеджеров. Чем более развиты компетенции, тем выше процент выполненных задач. Подтверждается аксиома - чем больше компетентны менеджеры, тем более они продуктивны;

Таблица 6

Результаты оценки взаимосвязи выполняемых задач и уровня развития компетенций

\begin{tabular}{|c|l|c|}
\hline $\begin{array}{c}\text { Номер } \\
\text { компе- } \\
\text { тенции }\end{array}$ & \multicolumn{1}{|c|}{ Компетенция (k) } & $\begin{array}{c}\text { Коэффициент } \\
\text { корреляции } \\
\text { Спирмена } \\
(p<0,05)\end{array}$ \\
\hline 1 & $\begin{array}{l}\text { Комплексное } \\
\text { многоуровневое } \\
\text { решение проблем }\end{array}$ & - \\
\hline 2 & Критическое мышление & - \\
\hline 3 & Креативность & 0,22754 \\
\hline 4 & Управление людьми & 0,20254 \\
\hline 5 & $\begin{array}{l}\text { Сотрудничество } \\
\text { с другими }\end{array}$ & - \\
\hline 6 & $\begin{array}{l}\text { Эмоциональный } \\
\text { интеллект }\end{array}$ & $\begin{array}{c}\text { Суждение и принятие } \\
\text { решений }\end{array}$ \\
\hline 7 & $\begin{array}{l}\text { Клиентоориенти- } \\
\text { рованность }\end{array}$ & - \\
\hline 9 & Умение вести переговоры & 0,22464 \\
\hline 10 & Когнитивная гибкость & - \\
\hline 11 & $\begin{array}{l}\text { Эффективный поиск } \\
\text { работы }\end{array}$ & 0,39092 \\
\hline
\end{tabular}

Источник. Авторская разработка по результатам мониторинга белорусских менеджеров. 
- самая активная компетенция (самый высокий коэффициент корреляции), позволяющая достигать выполнения максимального объема задач белорусскими менеджерами, эффективный поиск работы (коэф. 0,390), что указывает на высокую степень мобильности на национальном рынке труда;

- на более полное выполнение поставленных задач белорусскими менеджерами оказывают положительное влияние такие компетенции, как k3 (креативность), k4 (управление людьми), k6 (эмоциональный интеллект), k9 (умение вести переговоры), k11 (эффективный поиск работы).

Общий вывод полученных зависимостей: даже при выявленном недостаточном уровне развития современных (инновационных) компетенций, например креативности, они являются определяющими в эффективном функционировании белорусских менеджеров.

Количество времени, которое менеджер тратит на решение задач, поставленных перед ним и перед подчиненным ему подразделением, также информативно в оценках продуктивности менеджера. Шкала оценки количества затраченного времени находилась в диапазоне от менее 10\% до более 70\% рабочего времени. Общий результат представлен на рис. 5.

Подтверждается вывод о продуктивности менеджеров с более развитыми компетенциями: чем более они компетентны и профессиональны, тем быстрее выполняют поставленные задачи. Наблюдается белорусская особенность: у менеджеров со средним уровнем компетенций 19,5 (для выборки наших менеджеров это достаточно продуктивный уровень) затраты вре-

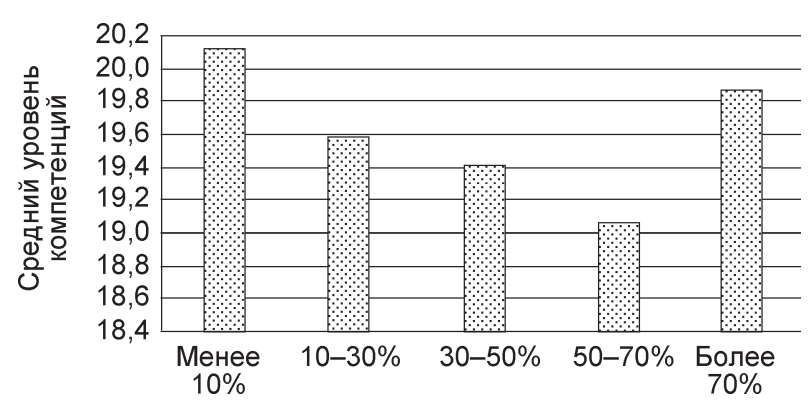

Рис. 5. Количество времени, затрачиваемое на выполнение задач, \%

Источник. Авторская разработка по результатам мониторинга белорусских менеджеров. мени на выполнение задач достаточно значительны (более 70\%). Это свидетельствует о необходимости дополнительного раунда исследований данной категории работников.

Для определения факторов и оценки степени эффективности деятельности белорусских менеджеров был использован регрессионный анализ на основе метода наименьших квадратов (МНК). Применение МНК стало возможным в генерировании линейной функции, которая, согласно определенным математическим критериям, наиболее соответствует нашим собранным данным.

В качестве главного параметра оценки (зависимой переменной) эффективной деятельности менеджера был выбран ответ на вопрос: на сколько процентов в среднем вы выполняете запланированные вами задачи? (варианты ответов: на 90\% и более; 70-89\%; $50-69 \%$; менее чем на $50 \%$; затрудняюсь ответить). В качестве зависимой (результативной) переменной взят процент выполнения запланированных задач.

Оценка эффективности функционирования белорусских менеджеров с учетом их профессиональных компетенций проводилась в несколько этапов.

Этап 1. Оценка зависимости эффективности работы менеджеров от среднего уровня компетенций в рамках исследовательской выборки. Результат такой оценки представлен в виде уравнения регрессии:

$$
y=0,67+0,12 \cdot k_{s},
$$

где $k_{s}$ - средний уровень компетенций.

Уравнение статистически значимо $(F=8,91, p<0,0039)$. Коэффициент детерминации небольшой, но статистически значимый $R^{2}=0,07$. Коэффициент регрессии $(0,12)$ положительный, т. е. чем выше уровень компетенций, тем больше процент выполнения задач. Такая положительная связь указывает и на то, что чем больше будут развиваться компетенции у белорусских менеджеров, тем больший объем задач они будут выполнять.

Этап 2. Оценка зависимости эффективности работы менеджеров от всех видов исследуемых профессиональных компетенций (k1.....k11). Она позволила определить, 
какие компетенции более всего влияют на деятельность белорусских менеджеров. Был использован метод пошаговой регрессии. Результаты анализа на основе 11 компетенций представлены в табл. 7.

Как видим, на первом шаге оценки получилось в целом статистически значимое уравнение регрессии $(F=2,61, p<0,005)$. Самый большой уровень значимости демонстрирует компетенция $\mathrm{k} 6(0,167)$ - эмоциональный интеллект. Это говорит о том, что белорусские менеджеры обладают той совокупностью навыков и способностей распознавать эмоции, понимать намерения, мотивацию и желания других людей, которые содействует эффективному выполнению управленческих задач. Эмоциональный интеллект - это «мякий» навык, оказывающий положительное влияние на способности к эффективному взаимодействию с подчиненными, основанному на эмоцио- нальных связях, и к эффективному управлению своими собственными эмоциями.

Далее, продолжая данный метод и используя второй шаг регрессии (исследование всех комбинаций, при которых возможны взаимосвязи), получили итоговое уравнение, в него вошли только четыре значимые компетенции (табл. 8).

Уравнение регрессии статистически значимое $\left(R^{2}=0,18, F=6,061, p<0,002\right)$, содержит две значимые переменные, k6 и k9. Коэффициенты при этих переменных положительные. Значит, при увеличении значения данных компетенций возрастает результативность работы менеджера. Полученная регрессионная зависимость объясняет всего $18 \%$ результирующего фактора. Предполагаем, что на работу менеджера оказывают влияние и другие факторы.

Этап 3. Включение в регрессию в качестве независимых тех переменных, кото-

Таблица 7

Результаты регрессии с включением всех компетенций (k1.....k11)

\begin{tabular}{|l|c|c|c|c|}
\hline \multicolumn{1}{|c|}{ Переменная } & Обозначение & $\begin{array}{c}\text { Коэффициент } \\
\text { регрессии } B\end{array}$ & $\begin{array}{c}\text { Критерий } \\
\text { Стьюдента } t \\
(100)\end{array}$ & $\begin{array}{c}\text { Уровень } \\
\text { значимости } \\
p \text {-знач. }\end{array}$ \\
\hline Свободный член & - & 0,023 & 0,03 & 0,980 \\
\hline $\begin{array}{l}\text { Комплексное многоуровневое } \\
\text { решение проблем }\end{array}$ & $\mathrm{k} 1$ & 0,082 & 1,33 & 0,187 \\
\hline Критическое мышление & $\mathrm{k} 2$ & 0,042 & 0,99 & 0,326 \\
\hline Креативность & $\mathrm{k} 3$ & 0,037 & 0,87 & 0,388 \\
\hline Управление людьми & $\mathrm{k} 4$ & 0,006 & 0,12 & 0,904 \\
\hline Сотрудничество с другими & $\mathrm{k} 5$ & 0,020 & 0,42 & 0,676 \\
\hline Эмоциональный интеллект & $\mathbf{k 6}$ & $\mathbf{0 , 1 6 7 *}$ & $\mathbf{3 , 0 8}$ & $\mathbf{0 , 0 0 3}$ \\
\hline Суждение и принятие решений & $\mathrm{k} 7$ & 0,057 & 1,07 & 0,285 \\
\hline Клиентоориентированность & $\mathrm{k} 8$ & 0,072 & 1,70 & 0,093 \\
\hline Умение вести переговоры & $\mathrm{k} 9$ & 0,084 & 1,55 & 0,124 \\
\hline Когнитивная гибкость & $\mathrm{k} 10$ & 0,072 & 1,65 & 0,102 \\
\hline Эффективный поиск работы & $\mathrm{k} 11$ & 0,050 & 1,24 & 0,219 \\
\hline
\end{tabular}

* Статистическая значимость при $p<0,05$.

Источник. Авторская разработка по результатам мониторинга белорусских менеджеров.

Таблица 8

Итоговый результат пошаговой регрессии

\begin{tabular}{|l|c|c|c|c|}
\hline \multicolumn{1}{|c|}{ Переменная } & Обозначение & $\begin{array}{c}\text { Коэффициент } \\
\text { регрессии } B\end{array}$ & $\begin{array}{c}\text { Критерий } \\
\text { Стьюдента } t(100)\end{array}$ & $\begin{array}{c}\text { Уровень } \\
\text { значимости } p \text {-знач. }\end{array}$ \\
\hline Свободный член & & 0,351 & 0,46 & 0,644 \\
\hline Эмоциональный интеллект & $\mathbf{k 6}$ & $\mathbf{0 , 1 4 5 *}$ & $\mathbf{2 , 9 6}$ & $\mathbf{0 , 0 0 4}$ \\
\hline Клиентоориентированность & $\mathrm{k} 8$ & 0,041 & 1,34 & 0,182 \\
\hline Умение вести переговоры & $\mathbf{k 9}$ & $\mathbf{0 , 1 0 6 *}$ & $\mathbf{2 , 2 3}$ & $\mathbf{0 , 0 2 8}$ \\
\hline Когнитивная гибкость & $\mathrm{k} 10$ & 0,066 & 1,69 & 0,095 \\
\hline
\end{tabular}

* Статистическая значимость при $p<0,05$.

Источник. Авторская разработка по результатам мониторинга белорусских менеджеров. 
рые характеризуют организацию и личностные параметры менеджеров. Результат оценки уравнения регрессии показал (табл. 9), что значимым является только один фактор - пол $(-0,407)$. Поэтому предполагаем, что мужчины-менеджеры работают более продуктивно. Дальнейший пошаговый метод не выявил значимого результата, то есть больше нет явных факторов, влияющих на эффективность работы менеджеров.

Этап 4. Оценка и анализ переменных, влияющих на стиль работы менеджеров. Оценивались переменные, определяющие стиль работы менеджеров, которые следуют из ответов на вопросы респондентам (например: на какой период вы обычно планируете свою деятельность? Расставляете ли вы регулярно приоритетность задач для ваших сотрудников? Каково ваше отношение к контролю подчиненных? и т. п.).

На первом шаге получили статистически значимое уравнение регрессии со всеми выбранными переменными (22 переменные (v1.... v22)) $\left(R^{2}=0,18, F=2,06\right.$, $p<0,006)$. Значимыми оказались только три переменных из 22: v6 (Расставляете ли вы регулярно приоритеты задач для ваших сотрудников?); v13 (Я обеспечиваю конкретную, конструктивную обратную связь, соблюдая баланс между отрицательным и положительным); v15 (Я предпринимаю усилия по нейтрализации факторов, негативно влияющих на мотивацию подчиненных). Однако данные переменные значимы лишь в общем контексте.
Для подтверждения объективной значимости выявленных переменных (или нахождения иных факторов) был предпринят второй шаг регрессии (исследование всех комбинаций, при которых возможны взаимосвязи). В результате получено итоговое статистически значимое уравнение $\left(R^{2}=0,25\right.$, $F=6,097, p<0,00002)$ с пятью значимыми объясняемыми переменными. Это позволило заключить, что на эффективность работы менеджеров влияют: а) регулярная расстановка приоритетов задач для подчиненных сотрудников (коэф. 1,746); б) выработка предложений и алгоритма достижения целей (коэф. 0,570); в) согласованность и эффективность проектов (коэф. 0,347); г) наличие обратной связи (коэф. 0,301); д) нейтрализация факторов, негативно влияющих на мотивацию подчиненных (коэф. 0,325). Чем чаще менеджер выполняет эти действия, тем выше его результативность.

Таким образом, общий итог совокупной оценки профессиональных компетенций (11 блоков) белорусских менеджеров с использованием 55 критериев, оценивающих степень развитости их управленческих компетенций, целесообразно представить следующим образом (табл. 10). Графически данный результат выглядит так (рис. 6).

Итак, в среде белорусских менеджеров среднего звена самый высокий уровень развития (20,8 балла) у такой компетенции, как сотрудничество с другими людьми, которая предполагает выстраивание взаимодействия с работниками в коллективе с

Таблица 9

Результат оценки с использованием параметров характеристики организации и менеджеров

\begin{tabular}{|l|c|c|c|c|}
\hline \multicolumn{1}{|c|}{ Переменная } & Обозначение & $\begin{array}{c}\text { Коэффициент } \\
\text { регрессии } B\end{array}$ & $\begin{array}{c}\text { Критерий } \\
\text { Стьюдента } t \\
(100)\end{array}$ & $\begin{array}{c}\text { Уровень } \\
\text { значимости } \\
p \text {-знач. }\end{array}$ \\
\hline Свободный член & - & 2,556 & 3,38 & 0,001 \\
\hline Численность подчиненных & $\mathrm{v} 27$ & 0,033 & 0,38 & 0,700 \\
\hline Численность организации & $\mathrm{v} 26$ & 0,144 & 1,65 & 0,100 \\
\hline $\begin{array}{l}\text { Самостоятельная организация } \\
\text { или филиал }\end{array}$ & $\mathrm{v} 25$ & 0,492 & 1,85 & 0,066 \\
\hline Управленческий стаж & $\mathrm{v} 22$ & 0,027 & 0,28 & 0,772 \\
\hline Возрастная группа & $\mathrm{v} 51$ & 0,035 & 0,22 & 0,819 \\
\hline Чтение публикаций & $\mathrm{v} 19$ & 0,100 & 1,15 & 0,251 \\
\hline Пол & $\mathbf{v 2 0}$ & $\mathbf{- 0 , 4 0 7 *}$ & $\mathbf{2 , 0 0}$ & $\mathbf{0 , 0 4 7}$ \\
\hline
\end{tabular}

* Статистическая значимость при $p<0,05$.

Источник. Авторская разработка по результатам мониторинга белорусских менеджеров. 
Совокупная оценка профессиональных компетенций белорусских менеджеров

\begin{tabular}{|c|c|c|c|}
\hline $\begin{array}{l}\text { Номер } \\
\text { блока }\end{array}$ & $\begin{array}{l}\text { Компетенция } \\
(\mathrm{k})\end{array}$ & Описание компетенции & $\begin{array}{c}\text { Средний } \\
\text { балл по всей } \\
\text { выборке }\end{array}$ \\
\hline 1 & $\begin{array}{l}\text { Комплексное } \\
\text { многоуровне- } \\
\text { вое решение } \\
\text { проблем }\end{array}$ & $\begin{array}{l}\text { Самостоятельное определение проблемы и всего комплекса } \\
\text { обуславливающих ее причин и источников; выявление } \\
\text { и устранение причины возникновения ситуации, а не ее следствий; } \\
\text { системный междисциплинарный подход к решению задач }\end{array}$ & 18,6 \\
\hline 2 & $\begin{array}{l}\text { Критическое } \\
\text { мышление }\end{array}$ & $\begin{array}{l}\text { Сомнение в достоверности всей поступающей информации, уже } \\
\text { существующих правил и даже своих представлений о мире; выбор } \\
\text { в качестве основы для решений и действий фактов }\end{array}$ & 19,7 \\
\hline 3 & Креативность & $\begin{array}{l}\text { Креативность. нестандартный подход в мышлении и поведении ко } \\
\text { всему, постоянное осознание и творческое развитие своего опыта; } \\
\text { инновационность и моделирование на основе интегрального } \\
\text { подхода и нелинейных решений }\end{array}$ & 18,2 \\
\hline 4 & $\begin{array}{l}\text { Управление } \\
\text { людьми }\end{array}$ & $\begin{array}{l}\text { Управление людьми, создание условий раскрытия творческого } \\
\text { потенциала и максимальных достижений у окружающих людей; } \\
\text { сочетание наличия «видения» решения ситуации и организации } \\
\text { людей на воплощение этого «видения» }\end{array}$ & 19,8 \\
\hline 5 & $\begin{array}{l}\text { Сотрудничест- } \\
\text { во с другими }\end{array}$ & $\begin{array}{l}\text { Выстраивание взаимодействия с людьми на различных уровнях - } \\
\text { от обмена информацией до обмена смыслами; создание общего } \\
\text { поля деятельности по решению задач }\end{array}$ & 20,8 \\
\hline 6 & \begin{tabular}{|l|} 
Эмоциональ- \\
ный интеллект
\end{tabular} & $\begin{array}{l}\text { Распознавание эмоций и понимание намерений других людей; } \\
\text { управление собственными эмоциями и состояниями; оказание } \\
\text { влияния на эмоции окружающих }\end{array}$ & 19,9 \\
\hline 7 & $\begin{array}{l}\text { Суждение } \\
\text { и принятие } \\
\text { решений }\end{array}$ & $\begin{array}{l}\text { Формирование собственного мнения и смелость в принятии } \\
\text { самостоятельных решений и их последствий }\end{array}$ & 19,9 \\
\hline 8 & \begin{tabular}{|l|} 
Клиентоориен- \\
тированность
\end{tabular} & $\begin{array}{l}\text { Взаимодействие с окружающими и решение проблем людей } \\
\text { на основе понимания их ценностей и потребностей }\end{array}$ & 19,8 \\
\hline 9 & $\begin{array}{l}\text { Умение вести } \\
\text { переговоры }\end{array}$ & $\begin{array}{l}\text { Коммуникация с позиции переговорного процесса, направленного } \\
\text { на долгосрочное сотрудничество; убедительное донесение своей } \\
\text { позиции через вербальные и невербальные техники с учетом } \\
\text { специфики и интересов второй стороны переговоров }\end{array}$ & 19,0 \\
\hline 10 & $\begin{array}{l}\text { Когнитивная } \\
\text { гибкость }\end{array}$ & $\begin{array}{l}\text { Оперативное переключение с одной мысли на другую, а также } \\
\text { обдумывание нескольких идей и задач одновременно }\end{array}$ & 19,4 \\
\hline 11 & $\begin{array}{l}\text { Эффективный } \\
\text { поиск работы }\end{array}$ & $\begin{array}{l}\text { Активное применение в поиске работы различных методов для } \\
\text { реализации оптимального сочетания потребностей работодателей, } \\
\text { тенденций развития профессиональной сферы и собственных } \\
\text { навыков и целей }\end{array}$ & 20,1 \\
\hline
\end{tabular}

Источник. Авторская разработка по результатам мониторинга белорусских менеджеров.

целью эффективного обмена информацией, создание информационной среды для решения задач.

Минимальный (начальный) уровень развития у таких компетенций, как креа-

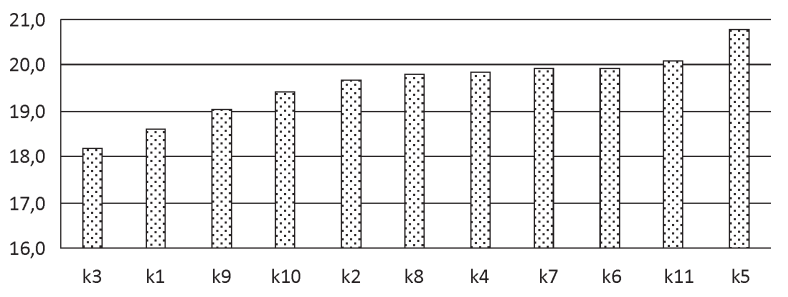

Рис. 6. Результат совокупной оценки профессиональных компетенций белорусских менеджеров

Источник. Авторская разработка по результатам мониторинга белорусских менеджеров. тивность и комплексное многоуровневое решение проблем. В связи с этим следует констатировать, что у белорусских менеджеров отсутствует профессиональный навык самостоятельного определения проблемы, ее предпосылок, нет навыков устранения причины возникновения ситуации, а не ее следствий. Они не моделируют креативное поведение, не используют нестандартные подходы в решении проблем, что ведет к минимизации возможностей генерирования инноваций.

В рамках всего исследования компетенций белорусских менеджеров сохраняется тенденция (по отраслям, профилям и т. д.) проявления всех видов компетенций. 
Больше всего выделялись компетенции «эффективный поиск работы» как самая активная и «креативность» как самая пассивная.

\section{$* \quad * \quad *$}

В среде белорусских менеджеров в целом не наблюдается начальный уровень развития компетенций soft skills, при котором менеджеры не способны выполнять свои функциональные обязанности. Уровень развития всех исследуемых компетенций находится в диапазоне 16-21 балл, в рамках которого они владеют ими ограниченно. Умение использовать новые и стандартные компетенции во внештатных ситуациях у белорусских менеджеров находится на этапе формирования.

В национальной экономике Беларуси уровень развития компетенций менеджеров среднего звена в формате soft skills характеризуется следующими особенностями:

- выполнение большого объема задач напрямую зависит от роста и развития их профессиональных компетенций;

• важной характеристикой белорусских менеджеров является эмоциональный интеллект. Это «мягкий» навык, от которого зависит эффективность взаимодействия с подчиненными;

- мужчины-менеджеры работают более продуктивно в отличие от женщин-менеджеров;

- на эффективность работы белорусских менеджеров в большей мере влияют такие факторы, как регулярность расстановки приоритетов задач для подчиненных сотрудников, наличие алгоритма достижения целей, а также обратной связи, согласованность проектов, нейтрализация факторов, негативно влияющих на мотивацию подчиненных.

\section{СПИСОК ЛИТЕРАТУРЫ (REFERENCES)}

Друкер П. 2004. Задачи менеджмента в XXI веке. Москва: Издательский дом «Вильямс». 272 с. [Drucker P. 2004. Management Challenges for the 21st Century. Moscow: Izdatel'skiy dom «Vil'yams». 272 p. (In Russ.)]

Ноакк Н.В., Костина Т.А., Ларин С.Н., Знаменская А.Н. 2020. Анализ динамики востребованности компетенций руководителей среднего звена управления. Международный журнал гуманитарных и естественных наук. № 4-3. С. 6076. [Noakk N.V., Kostina T.A., Larin S.N., Znamenskaya A.N. 2020. Analysis of the dynamics of the requirement of competencies of heads of the middle management. Mezhdunarodnyy zhurnal gumanitarnykh i estestvennykh nauk. № 4-3. PP. 60-76. (In Russ.)]

Спенсер-мл. Л.М., Спенсер С.М. 2010. Компетениии на работе. Модели максимальной эффективности работьы. Москва: НІРРО. 384 с. [Spencer L.M., Spencer S.M. 2010. Competence at work. Models for Superior Performance. Moscow: HIPPO. 384 p. (In Russ.)]

Уиддет С., Холлифорд С. 2008. Руководство по компетенииям. Москва: НІРРО. 218 с. [Whiddett S., Hollyforde S. 2008. The competencies handbook. Moscow: HIPPO. 218 p. (In Russ.)]

Laguna M., Wiechetek M., Talik W. 2012. Competencies of Managers and Their Business Success. Central European Business Review. Vol. 1. No 3. PP. 7-13. DOI: $10.18267 /$ j.cebr.25

Robinson M., Sparrow P., Clegg C., Birdi K. 2005. Design engineering competencies: Future requirements and predicted changes in the forthcoming decade. Design Studies. Vol. 26. Iss. 2. PP. 123-153. DOI:10.1016/J.DESTUD.2004.09.004 
In citation: Belorusskiy Ekonomicheskiy zhurnal. 2021. No 4. PP. 41-54.

Belarusian Economic Journal. 2021. No 4. PP. 41-54.

\title{
POTENTIAL FOR DEVELOPING PROFESSIONAL COMPETENCIES OF MANAGERS IN THE BELARUSIAN ECONOMY
}

\author{
Nataliya Makovskaya ${ }^{1}$ \\ Author affiliation: 1 A. Kuleshov Mogilev State University (Mogilev, Belarus). \\ Corresponding author: Nataliya Makovskaya (maknata@mail.ru).
}

ABSTRACT. The article presents the results of a scientific study of professional competencies (soft skills) of managers in the national economy of Belarus. Criteria and a scale for assessing the development and availability of a set of professional skills and competencies of managers are determined. Trends and thresholds of criticality in the development of professional competencies of Belarusian managers in the context of innovation and digitalization of the national economy of Belarus are revealed.

KEYWORDS: manager, professional competence, labour productivity, types of economic activity, working hours, labour market.

JEL-code: J24, J31, J44.

DOI: $10.46782 / 1818-4510-2021-4-41-54$

Received 25.08.2021 